\title{
Isolation and anti-HIV-1 integrase activity of lentzeosides A-F from extremotolerant lentzea sp. H45, a strain isolated from a high-altitude Atacama Desert soil
}

\author{
Dominik Wichner ${ }^{1,2}$, Hamidah Idris ${ }^{3}$, Wael E Houssen ${ }^{1,4,5}$, Andrew R McEwan ${ }^{1,4}$, Alan T Bull ${ }^{6}$, \\ Juan A Asenjo ${ }^{7}$, Michael Goodfellow ${ }^{3}$, Marcel Jaspars ${ }^{1}$, Rainer Ebel ${ }^{1}$ and Mostafa E Rateb ${ }^{1,8,9}$
}

The extremotolerant isolate $\mathrm{H} 45$ was one of several actinomycetes isolated from a high-altitude Atacama Desert soil collected in northwest Chile. The isolate was identified as a new Lentzea sp. using a combination of chemotaxonomic, morphological and phylogenetic properties. Large scale fermentation of the strain in two different media followed by chromatographic purification led to the isolation of six new diene and monoene glycosides named lentzeosides $A-F$, together with the known compound (Z)-3-hexenyl glucoside. The structures of the new compounds were confirmed by HRESIMS and NMR analyses. Compounds 1-6 displayed moderate inhibitory activity against HIV integrase.

The Journal of Antibiotics (2017) 70, 448-453; doi:10.1038/ja.2016.78; published online 29 June 2016

\section{INTRODUCTION}

Natural products are known to be a rich source of diverse chemical scaffolds for drug discovery. However, their use has diminished in the past two decades, mainly due to technical barriers when screening natural products in high-throughput assays against molecular targets and to their limited availability for clinical trials. ${ }^{1}$ In addition, the discovery of new bioactive natural products is challenging due to the high rate of re-discovery of known metabolites, a problem that can be addressed by isolating and screening novel microorganisms from underexplored habitats, such as desert biomes ${ }^{2,3}$ and by incorporating rigorous dereplication procedures into all stages of the discovery process. In addition, industry has realized that phenotypic screening is more effective at discovering new bioactive compounds than narrow screening of molecular targets.

The Atacama Desert in Chile is known for its extreme aridity which has persisted for at least $\sim 15$ million years. ${ }^{4}$ Some regions in the desert were once thought to have 'Mars-like' soils deemed too extreme for life to exist given high levels of UV radiation, the presence of inorganic oxidants, areas of high salinity and very low concentrations of organic carbon. ${ }^{5}$ However, recent research has revealed extraordinary bacterial diversity across a range of Atacama environments, ${ }^{6,7}$ and many novel actinomycetes have been isolated from hyper-and extreme hyper-arid soils. ${ }^{89}$ Biological and genome-guided screening of some of these actinomycetes has led to the isolation and characterization of new natural products belonging to diverse structural classes and exhibiting various biological activities, as exemplified by the antimicrobial chaxamycins and chaxalactins isolated from Streptomyces leeuwenhoekii $\mathrm{C}_{4} 4^{\mathrm{T}}$, the abenquines from Streptomyces sp. DB634, the antitumor atacamycins from Streptomyces sp. C38 and the cell invasion inhibitor chaxapeptin from S. leeuwenhoekii strain C58. ${ }^{10-16}$

As part of our ongoing program to investigate the extremobiosphere as a source of new natural products, we have focused our attention on Lentzea sp. strain $\mathrm{H} 45$ which was isolated from a high-altitude Atacama Desert soil and shown to produce a specific pattern of secondary metabolites based on its liquid chromatography MS (LCMS) profile and associated NMR data. Chemical screening of the strain on two different cultivation media led to the isolation of six new and one known diene, as well as monoene glycosides (Figure 1). Structure elucidation of these compounds was based on high resolution electrospray ionization mass spectrometry (HRESIMS), 1D and 2D NMR analyses. The isolated compounds were screened for their inhibitory activity against HIV-1 integrase, an enzyme that is critical for the integration of the HIV genome into the host genome. ${ }^{17,18}$ This target is very attractive for the development of new anti-HIV therapy as it is selective for the virus.

${ }^{1}$ Marine Biodiscovery Centre, Department of Chemistry, University of Aberdeen, Scotland, UK; ${ }^{2}$ Department of Chemistry, University of Regensburg, Universitätsstraße 31, Regensburg, Germany; ${ }^{3}$ School of Biology, Newcastle University, Newcastle upon Tyne, UK; ${ }^{4}$ Institute of Medical Sciences, University of Aberdeen, Scotland, UK; ${ }^{5}$ Faculty of Pharmacy, Department of Pharmacognosy, Mansoura University, Mansoura, Egypt; ${ }^{6}$ School of Biosciences, University of Kent, Kent, UK; ${ }^{7}$ Centre for Biotechnology and Bioengineering (CeBiB), Department of Chemical Engineering and Biotechnology, Universidad de Chile, Santiago, Chile; ${ }^{8}$ School of Science \& Sport, University of the West of Scotland, Paisley, UK and ${ }^{9}$ Department of Pharmacognosy, School of Pharmacy, Beni-Suef University, Beni-Suef, Egypt Correspondence: Dr ME Rateb, School of Science \& Sport, University of the West of Scotland, Paisley PA1 $2 B E$, UK.

E-mail: mostafa.rateb@uws.ac.uk

Received 4 March 2016; revised 10 May 2016; accepted 31 May 2016; published online 29 June 2016 


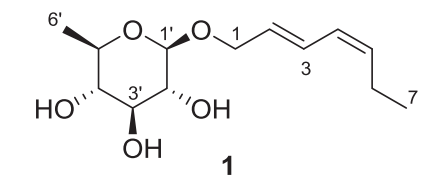<smiles>CC/C=C\C=C\CO[C@H]1O[C@H](C)C(O)[C@H](O)[C@H]1O</smiles><smiles>CC/C=C\C=C\COC1O[C@H](CO)[C@@H](O)C(O)[C@H]1O</smiles><smiles>CC/C=C/C=C/CO[C@H]1O[C@H](C)[C@H](O)[C@H](O)[C@H]1O</smiles><smiles>C/C=C\CCO[C@H]1O[C@H](C)[C@@H](O)[C@H](O)[C@H]1O</smiles><smiles>CCCCCOC1OC(C)[C@H](O)C(O)C1O</smiles><smiles>CC/C=C\CCOC1OC(CO)[C@H](O)C(O)C1O</smiles>

Figure 1 Compounds isolated from Lentzea sp. H45.

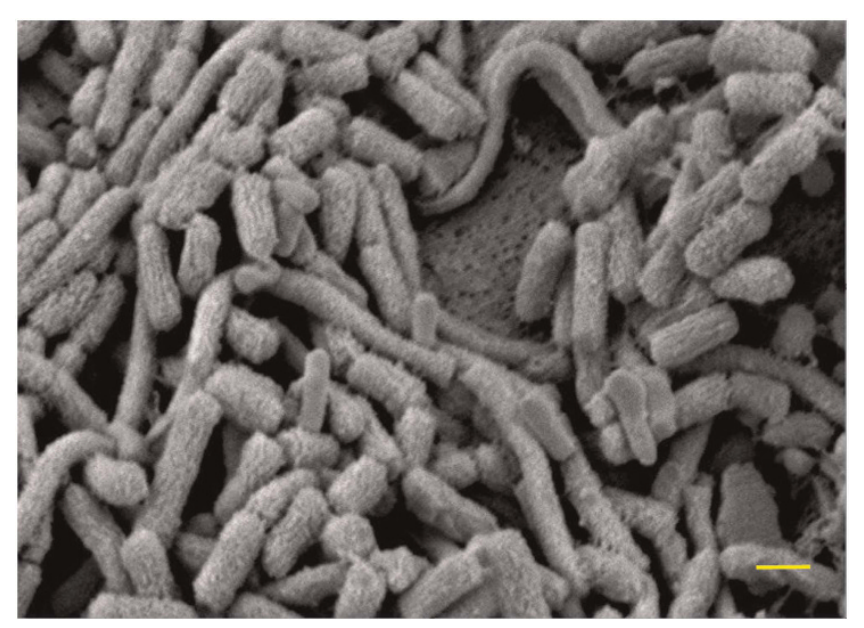

Figure 2 Scanning electron micrograph of Lentzea sp. H45 showing fragmentation of aerial hyphae into rod-shaped elements following growth on ISP 3 (International Streptomyces Project) agar after incubation at $28{ }^{\circ} \mathrm{C}$ for 10 days. Bar, $1 \mu \mathrm{m}$. A full color version of this figure is available at The Journal of Antibiotics journal online.

\section{RESULTS}

In this study, actinobacterial isolate $\mathrm{H} 45$ was obtained from subsurface soil sample collected at an altitude $>5000 \mathrm{~m}$ in the vicinity of the ALMA Observatory in the Atacama Desert, Chile. The chemotaxonomic, morphological, physiological and phylogenetic properties of strain $\mathrm{H} 45$ are in line with its classification in the genus Lentzea. ${ }^{19,20}$ The strain was found to be an aerobic, Gram-positive actinomycete that formed a branched substrate mycelium and aerial hyphae that fragmented into rod-shaped elements (Figure 2), while chemical analysis of whole-organism hydrolysates revealed the presence of meso-diaminopimelic acid and galactose, mannose and ribose, and the predominant isoprenologue was tetrahydrogenated menaquinone with nine isoprene units (MK9[H4]). The organism formed a distinct branch at the periphery of the Lentzea 16S ribosomal RNA (rRNA) gene tree, a position that was supported by all of the tree-making algorithms and by a $69 \%$ bootstrap value (Figure 3 ). The strain was most closely, albeit loosely, related to Lentzea kentuckyensis ${ }^{T}$ NRRL B-34416. These results clearly show that the isolate forms a new centre of taxonomic variation in the genus Lentzea consistent with its recognition as a putative new species.

Large scale fermentation of Lentzea sp. strain H45 on two different media supplemented with Diaion HP-20 resin was followed by methanolic extraction of the resin beads; subsequently, the crude extract was subject to multiple steps of medium and high pressure pr-

eparative C18 chromatography which resulted in the isolation of six new and one known natural product based on HRESIMS and NMR data (Figure 1).

HRESIMS analysis of compound 1 yielded a $[\mathrm{M}+\mathrm{Na}]^{+}$ion at $m / z$ 281.1351 indicating a molecular formula of $\mathrm{C}_{13} \mathrm{H}_{22} \mathrm{O}_{5}$. The analysis of ${ }^{1} \mathrm{H},{ }^{13} \mathrm{C}$ and multiplicity-edited HSQC NMR spectra revealed the presence of one methylene $\left(\delta_{\mathrm{C}} / \delta_{\mathrm{H}} 20.5 / 2.16\right)$ and one oxymethylene group $\left(\delta_{\mathrm{C}} / \delta_{\mathrm{H}} 68.3 / 4.26,4.08\right)$, one methyl doublet $\left(\delta_{\mathrm{C}} / \delta_{\mathrm{H}} 17.9 / 1.15\right)$, one methyl triplet $\left(\delta_{\mathrm{C}} / \delta_{\mathrm{H}} 14.2 / 0.94\right)$, four olefinic resonances $\left(\delta_{\mathrm{C}} / \delta_{\mathrm{H}}\right.$ $133.7 / 5.42,129.6 / 5.71,127.4 / 5.94$ and 127.0/6.58) and five oxymethine groups $\left(\delta_{\mathrm{C}} / \delta_{\mathrm{H}} \quad 102.1 / 4.15, \quad 76.4 / 3.09, \quad 75.3 / 2.80, \quad 73.7 / 2.98\right.$ and 71.5/3.15). Furthermore, the ${ }^{1} \mathrm{H}$ NMR spectrum showed 3 hydroxy groups resonating at $\delta_{\mathrm{H}} 4.8-5.1$. The COSY correlations of $\mathrm{H}_{2}-1$ through $\mathrm{H}_{3}-7$ indicated a spin system comprising two conjugated olefins with a terminal ethyl group and established a $(2 E, 4 Z)$ heptadien-1-ol substructure (Figure 4). This was corroborated by the HMBC correlations of $\mathrm{H}_{2}-1 / \mathrm{C}-3, \mathrm{H}-2 / \mathrm{C}-4$ and $\mathrm{H}_{3}-7$ to both $\mathrm{C}-5$ and C-6 (Figure 4). The COSY spectrum indicated a second spin system which included the signals $\mathrm{H}-1^{\prime}$ to $\mathrm{H}_{3}-6^{\prime}$, which in combination with the $\mathrm{HMBC}$ correlation of $\mathrm{H}-1^{\prime} / \mathrm{C}-5^{\prime}$ suggested a $\beta$-L-quinovopyranose ( $\beta$-L-6-deoxyglucopyranose), which was confirmed by the optical rotation, the coupling constant of the anomeric proton $(J=7.8 \mathrm{~Hz})$, axial-axial proton couplings for $\mathrm{H} 1^{\prime} / \mathrm{H}^{\prime}$, $\mathrm{H} 2^{\prime} / \mathrm{H}^{\prime}, \mathrm{H}^{\prime} / \mathrm{H}^{\prime}{ }^{\prime}$ and $\mathrm{H}^{\prime} / \mathrm{H}^{\prime}$ (Table 2) as well as the agreement of the ${ }^{13} \mathrm{C}$ NMR data and the ROESY correlations with reported data. ${ }^{21}$ The sugar moiety was further confirmed by acid hydrolysis of 1 upon which $\alpha$-L-quinovose was detected by co-chromatography on TLC in comparison with authentic sugar samples. Finally, the connectivity of the two substructures was confirmed by the HMBC correlation of $\mathrm{H}-1^{\prime} / \mathrm{C}-1$. The geometry of the two double bonds was established as $(2 E, 4 Z)$ based on coupling constant data of $\mathrm{H}-2$ and $\mathrm{H}-5$ with values of 16.1 and $10.1 \mathrm{~Hz}$, respectively, which was further supported by ROESY correlations of $\mathrm{H}-2 / \mathrm{H}-4, \mathrm{H}-3 / \mathrm{H}_{2}-1, \mathrm{H}-4 / \mathrm{H}-5$ and $\mathrm{H}-3 / \mathrm{H}_{2}-6$ (Figure 4). Based on this evidence, 1 was identified as a new natural product for which the name lentzeoside $\mathrm{A}$ is proposed.

Compound 2 shared the chemical formula with 1 as $\mathrm{C}_{13} \mathrm{H}_{22} \mathrm{O}_{5}$ based on the HRESIMS analysis that gave an $[\mathrm{M}+\mathrm{Na}]^{+}$ion at $m / z$ 281.1351. Comparison of the ${ }^{1} \mathrm{H}$ and ${ }^{13} \mathrm{C}$ NMR data of 2 with those obtained for $\mathbf{1}$ revealed that $\mathbf{2}$ was the $1^{\prime}$-epimer of $\mathbf{1}$, and the presence of an $\alpha$-L-rhamnopyranose was corroborated by the optical rotation, the very small coupling of the anomeric proton and the agreement of the ${ }^{13} \mathrm{C}$ NMR data and the ROESY correlations with the reported data. ${ }^{22}$ The sugar moiety was further confirmed by acid hydrolysis of $\mathbf{2}$ on which $\alpha$-L-rhamnose was detected by co-chromatography on TLC in comparison with authentic sugar samples. Thus, compound 2 was 


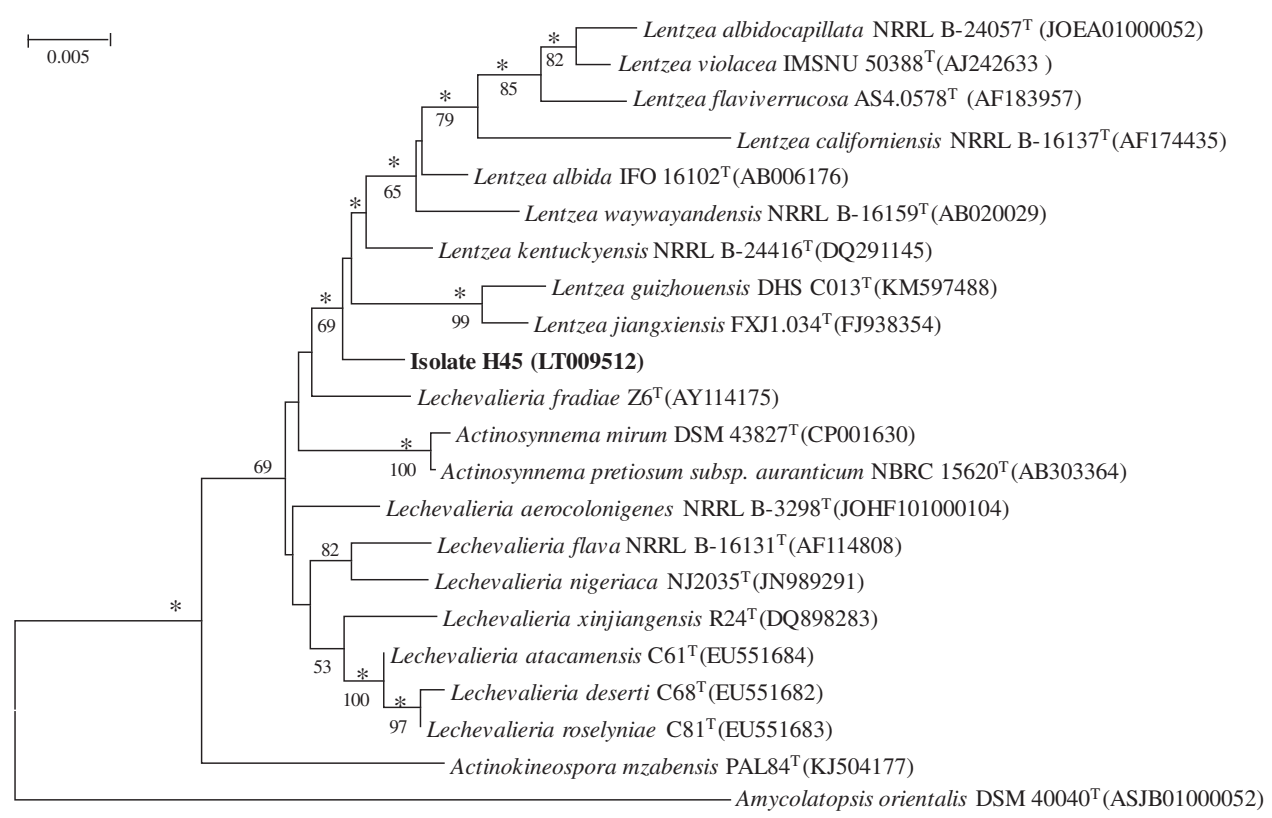

Figure 3 Neighbor-joining phylogenetic tree based on $16 S$ rRNA gene sequences showing relationships between isolate $\mathrm{H} 45$ and the type strains of Lentzea and Lechevalieria species. Asterisks indicate branches of the tree that were also recovered using the maximum-likelihood and maximum-parsimony tree-making methods. Numbers at the nodes indicate levels of bootstrap support based on a neighbor-joining analysis of 1000 resampled data sets, only values above $50 \%$ are shown.
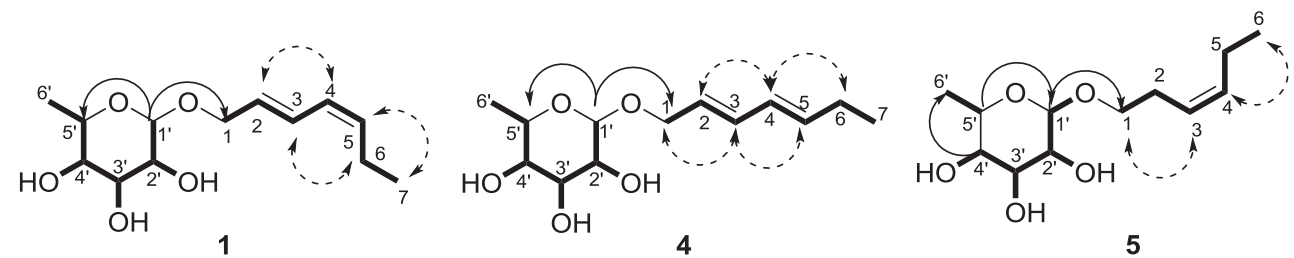

Figure 4 Key COSY, HMBC and ROESY correlations of compounds 1, 4 and 5.

identified as a new secondary metabolite for which we propose the name lentzeoside $\mathrm{B}$.

The molecular formula $\mathrm{C}_{13} \mathrm{H}_{22} \mathrm{O}_{6}$ for compound 3 was established on the basis of HRESIMS analysis that afforded an $[\mathrm{M}+\mathrm{Na}]^{+}$ion at $\mathrm{m} / \mathrm{z} 297.1299$ indicating one more oxygen atom than in 1 . The ${ }^{1} \mathrm{H},{ }^{13} \mathrm{C}$ NMR and multiplicity-edited HSQC spectra showed a close similarity to those obtained for $\mathbf{1}$, but indicated that the $\beta$-L-rhamnopyranose unit in $\mathbf{1}$ had been replaced by a $\beta$-D-glucopyranose. This assumption was confirmed by the optical rotation, the maganitude of the coupling constant analysis of the anomeric proton $(J=7.9 \mathrm{~Hz})$ as well as the agreement of the ${ }^{13} \mathrm{C}$ NMR data and the ROESY correlations with the reported data. ${ }^{23}$ The sugar moiety was further confirmed by acid hydrolysis of $\mathbf{3}$ on which $\beta$-D-glucose was detected by co-chromatography on TLC in comparison with authentic sugar samples. Therefore, the structure of $\mathbf{3}$ was established as depicted, representing a new natural product for which the name lentzeoside $\mathrm{C}$ is proposed.

The HRESIMS analysis of compound 4 provided a $[\mathrm{M}+\mathrm{Na}]^{+}$ion at $\mathrm{m} / \mathrm{z} 281.1349$ indicating it to be an isomer of 2. Analysis of the NMR spectra and the optical rotation indicated that the two compounds contained a $\alpha$-L-rhamnopyranose, but differed in the geometry of the diene moiety. The coupling constant data of $\mathrm{H}-2$ and $\mathrm{H}-5$ with values of 16.1 and $15.5 \mathrm{~Hz}$, respectively, indicated E-configurations for both olefinic groups in 4 . This was further supported by the ROESY correlations of $\mathrm{H}_{2}-1 / \mathrm{H}-3, \mathrm{H}-3 / \mathrm{H}-5$,
$\mathrm{H}-2 / \mathrm{H}-4$ and $\mathrm{H}-4 / \mathrm{H}_{2}-6$ (Figure 4). On that basis, 4 was identified as a new secondary metabolite for which the name lentzeoside $\mathrm{D}$ is proposed.

The molecular formula of compounds $\mathbf{5}$ and $\mathbf{6}$ was deduced as $\mathrm{C}_{12} \mathrm{H}_{22} \mathrm{O}_{5}$ as HRESIMS analysis of $[\mathrm{M}+\mathrm{Na}]^{+}$and $[\mathrm{M}+\mathrm{H}]^{+}$ions at $\mathrm{m} / \mathrm{z}$ 269.1351 and 247.1545, respectively, indicating one carbon atom $<1$. NMR analysis and optical rotation of $\mathbf{5}$ and $\mathbf{6}$ indicated that they contained an $\alpha$-L-rhamnopyranose and a $\beta$-L-quinovopyranose as described above for $\mathbf{2}$ and $\mathbf{1}$, respectively, which was connected to the same (Z)-3-hexenyl side chain. The presence of the latter was evident from COSY correlations of $\mathrm{H}_{2}-1$ through $\mathrm{H}_{3}-6$. As the signals for $\mathrm{H}-3$ and $\mathrm{H}-4$ exhibited non-first order coupling, the E-configuration of the double bond was established based on ROESY correlations of $\mathrm{H}_{2}-1 / \mathrm{H}-3, \mathrm{H}-4 / \mathrm{H}_{3}-6$ and $\mathrm{H}_{2}-2 / \mathrm{H}_{2}-5$ (Figure 4). Based on this information, compounds 5 and $\mathbf{6}$ were identified as new natural products for which the names lentzeoside $\mathrm{E}$ and $\mathrm{F}$, respectively, are proposed.

Based on the NMR and accurate mass analyses, compound 7 was identified as ( $Z$ )-3-hexenyl glucoside, this compound has been isolated from several plant sources, such as Epimedium grandiflorum. ${ }^{24}$

Compounds 1-6 were evaluated for their anti-HIV integrase activity at different concentrations. Compounds 3, 4 and $\mathbf{5}$ inhibited HIV integrase with $\mathrm{IC}_{50}$ values of 21,16 and $21 \mu \mathrm{M}$, respectively. Compounds 1, 2 and 6 were only weakly active, they did not give $50 \%$ inhibition of the enzyme activity up to a concentration of $100 \mu \mathrm{M}$. 
Table $1{ }^{13} \mathrm{C}(150 \mathrm{MHz})$ NMR spectroscopic data for lentzeosides A-F (1-6) in DMSO- $d_{6}$

\begin{tabular}{|c|c|c|c|c|c|c|}
\hline & 1 & 2 & 3 & 4 & 5 & 6 \\
\hline 2 & $129.6, \mathrm{CH}$ & $129.5, \mathrm{CH}$ & $129.6, \mathrm{CH}$ & $127.1, \mathrm{CH}$ & $27.2, \mathrm{CH}$ & $27.6, \mathrm{CH}$ \\
\hline 3 & $127.0, \mathrm{CH}$ & $127.2, \mathrm{CH}$ & $127.1, \mathrm{CH}$ & $132.5, \mathrm{CH}$ & $125.4, \mathrm{CH}$ & $125.2, \mathrm{CH}$ \\
\hline 4 & $127.4, \mathrm{CH}$ & $127.3, \mathrm{CH}$ & $127.4, \mathrm{CH}$ & $128.5, \mathrm{CH}$ & $133.0, \mathrm{CH}$ & $132.9, \mathrm{CH}$ \\
\hline 7 & $14.2, \mathrm{CH}_{3}$ & $14.1, \mathrm{CH}_{3}$ & $14.2, \mathrm{CH}_{3}$ & $13.4, \mathrm{CH}_{2}$ & - & - \\
\hline $1^{\prime}$ & $102.1, \mathrm{CH}$ & $99.3, \mathrm{CH}$ & $102.0, \mathrm{CH}$ & $99.1, \mathrm{CH}$ & $99.9, \mathrm{CH}$ & 102.7, $\mathrm{CH}$ \\
\hline $2^{\prime}$ & $73.7, \mathrm{CH}$ & 70.7, CH & $73.5, \mathrm{CH}$ & 70.7, CH & $70.7, \mathrm{CH}$ & 73.6, $\mathrm{CH}$ \\
\hline $3^{\prime}$ & $76.4, \mathrm{CH}$ & $70.5, \mathrm{CH}$ & 76.7, $\mathrm{CH}$ & $70.5, \mathrm{CH}$ & $70.5, \mathrm{CH}$ & $76.5, \mathrm{CH}$ \\
\hline $4^{\prime}$ & $75.3, \mathrm{CH}$ & 72.0, $\mathrm{CH}$ & $68.2, \mathrm{CH}$ & $72.0, \mathrm{CH}$ & 72.0, $\mathrm{CH}$ & $75.3, \mathrm{CH}$ \\
\hline $5^{\prime}$ & $71.5, \mathrm{CH}$ & $68.5, \mathrm{CH}$ & $76.9, \mathrm{CH}$ & $68.5, \mathrm{CH}$ & $68.4, \mathrm{CH}$ & $71.5, \mathrm{CH}$ \\
\hline
\end{tabular}

Table $2{ }^{1} \mathrm{H}(600 \mathrm{MHz})$ NMR spectroscopic data for lentzeosides A-F (1-6) in DMSO- $d_{6}$

\begin{tabular}{|c|c|c|c|c|c|c|}
\hline & 1 & 2 & 3 & 4 & 5 & 6 \\
\hline Position & $\delta_{\mathrm{H}}$, mult. $(J$ in $\mathrm{Hz})$ & $\delta_{\mathrm{H}}$, mult. $(\mathrm{J}$ in $\mathrm{Hz})$ & $\delta_{\mathrm{H}}$, mult. $(\mathrm{J}$ in $\mathrm{Hz})$ & $\delta_{\mathrm{H}}$, mult. $(\mathrm{J}$ in $\mathrm{Hz})$ & $\delta_{\mathrm{H}}$, mult. $(\mathrm{J}$ in $\mathrm{Hz})$ & $\delta_{\mathrm{H}}$, mult. $(J$ in $\mathrm{Hz})$ \\
\hline \multirow[t]{2}{*}{1} & $4.26(d d, 13.2,5.4)$ & $4.11(\mathrm{dd}, 12.9,5.3)$ & $4.32(d d, 13.7,5.8)$ & $4.06(\mathrm{dd}, 12.2,5.3)$ & $3.51(\mathrm{~m})$ & $3.66(\mathrm{~m})$ \\
\hline & $4.08(d d, 13.1,5.2)$ & $3.97(d d, 12.7,5.2)$ & $4.10(\mathrm{dd}, 13.6,6.5)$ & $3.91(\mathrm{dd}, 12.4,5.1)$ & & $3.42(\mathrm{~m})$ \\
\hline 2 & $5.71(\mathrm{dt}, 16.1,6.3)$ & $5.73(\mathrm{dt}, 15.9,6.1)$ & $5.73(\mathrm{dt}, 15.7,5.9)$ & $5.63(\mathrm{dt}, 16.1,5.8)$ & $2.24(\mathrm{~m})$ & $2.26(\mathrm{~m})$ \\
\hline 3 & $6.58(t, 14.5)$ & $6.51(t, 14.2)$ & $6.59(\mathrm{dd}, 15.2,11.2)$ & $6.18(t, 15.3)$ & $5.32(\mathrm{~m})$ & $5.33(\mathrm{~m})$ \\
\hline 4 & $5.94(\mathrm{t}, 11.2)$ & $5.96(t, 11.3)$ & $5.96(t, 11.1)$ & $6.04(t, 15.1)$ & $5.42(\mathrm{~m})$ & $5.42(\mathrm{~m})$ \\
\hline 5 & $5.42(\mathrm{dt}, 10.1,6.7)$ & $5.43(\mathrm{dt}, 10.5,6.2)$ & $5.42(\mathrm{dt}, 10.9,6.5)$ & $5.75(\mathrm{dt}, 15.5,6.5)$ & $2.01(\mathrm{~m})$ & $2.01(\mathrm{~m})$ \\
\hline 6 & $2.16(\mathrm{~m})$ & $2.16(\mathrm{~m})$ & $2.16(\mathrm{~m})$ & $2.07(\mathrm{~m})$ & $0.92(t, 7.6)$ & $0.92(t, 7.6)$ \\
\hline 7 & $0.94(t, 7.5)$ & $0.95(t, 7.5)$ & $0.94(t, 7.5)$ & $0.96(t, 7.4)$ & & \\
\hline $1^{\prime}$ & $4.15(\mathrm{~d}, 7.8)$ & 4.57 (br s) & $4.15(d, 7.9)$ & $4.56(\mathrm{br} \mathrm{s})$ & 4.54 (br s) & $4.12(d, 7.8)$ \\
\hline $2^{\prime}$ & $2.98(t, 7.5)$ & $3.41(\mathrm{~m})$ & $2.97(\mathrm{~m})$ & $3.40(\mathrm{~m})$ & $3.39(\mathrm{~m})$ & $2.94(t, 7.9)$ \\
\hline $3^{\prime}$ & $3.09(t, 8.6)$ & 3.60 (br s) & $3.12(t, 7.6)$ & 3.59 (br s) & 3.57 (br s) & $3.08(t, 8.8)$ \\
\hline $4^{\prime}$ & $2.80(t, 7.6)$ & $3.18(\mathrm{~m})$ & $3.04(\mathrm{~m})$ & $3.17(\mathrm{~m})$ & $3.17(t, 8.9)$ & $2.79(t, 8.6)$ \\
\hline $5^{\prime}$ & $3.15(\mathrm{~m})$ & $3.38(\mathrm{~m})$ & $3.05(\mathrm{~m})$ & $3.38(\mathrm{~m})$ & $3.37(\mathrm{~m})$ & $3.15(\mathrm{~m})$ \\
\hline $6^{\prime}$ & $1.15(\mathrm{~d}, 6.1)$ & $1.14(\mathrm{~d}, 6.4)$ & $\begin{array}{c}3.66(\mathrm{dd}, 11.5,5.6) \\
3.43(\mathrm{~m})\end{array}$ & $1.13(\mathrm{~d}, 6.1)$ & $1.12(\mathrm{~d}, 6.3)$ & $1.14(\mathrm{~d}, 6.3)$ \\
\hline $\mathrm{OH}-2^{\prime}$ & 5.07 (br s) & & $5.08(d, 4.4)$ & 4.74 (br s) & 4.72 (br s) & $4.91(\mathrm{~d}, 18.1)$ \\
\hline $\mathrm{OH}-3^{\prime}$ & 4.96 (br s) & & $4.91(d, 3.9)$ & & 4.51 (br s) & 4.94 (br s) \\
\hline $\mathrm{OH}-4^{\prime}$ & $4.96(\mathrm{br} \mathrm{s})$ & & $4.96(\mathrm{br} \mathrm{s})$ & 4.47 (br s) & $4.70(\mathrm{br} \mathrm{s})$ & $4.91(\mathrm{br} \mathrm{s})$ \\
\hline $\mathrm{OH}-6^{\prime}$ & & & $4.49(t, 5.7)$ & & & \\
\hline
\end{tabular}

\section{DISCUSSION}

A major draw of filamentous actinomycetes, especially streptomycetes, is their unrivaled capacity to synthesize structurally diverse bioactive metabolites. In this context, the present study provides further evidence that taxonomically novel actinomycetes isolated from Atacama Desert soils are a rich source of new chemical entities. It is especially interesting that the new compounds, lentzosides A-F, are derived from a novel Lentzia strain as previously new specialized metabolites from Atacama Desert actinomycetes have come from novel Streptomyces strains, ${ }^{7}$ notably from a deep seated $16 S$ rRNA gene clade that can be equated with the species, Streptomyces leeuwenhoekii. ${ }^{10-16}$ The genus Lentzia was validly published in $1995,{ }^{25}$ but to date does not appear to have been studied in terms of its natural product chemistry, though Lentzia sp. 7887 effects the biotransformation of FR901459, a novel derivative of cyclosporin. ${ }^{26}$
Chemical screening of this novel Lentzia sp. strain H45 on two different media led to the isolation of six new diene and monoene glycosides and the known compound (Z)-3-hexenyl glucoside. It is interesting to note that this class of metabolites was not traced before from microbial sources and the most closely related known compound 7 which was also encountered in the present study had previously been obtained from plant sources. Owing to the close similarity of lentzeosides, it could be argued that they were artifacts rather than natural products. To preclude this assumption and confirm them as natural products, they were directly detected by LCMS analysis of the fresh bacterial culture broth before the inclusion of the Diaion HP-20, extraction and purification process with the exact retention times, UV absorption and accurate mass.

Compounds 1-6 were found to inhibit HIV-1 integrase in vitro. Treatment of HIV usually involves a combination therapy of different 
drugs that target different stages of the viral replication cycle, a procedure that overcomes the development of resistance in the virus due to its high mutation rate. ${ }^{27} \mathrm{HIV}$ integrase is one of the key enzymes in the virus replication cycle as it is responsible for the integration of the reverse transcribed viral complementary DNA (cDNA) into the host cell genome. ${ }^{28}$ Raltegravir is the first FDA clinically approved HIV integrase inhibitor used to treat both HIV-1 infections in treatment-experienced adult patients who have evidence of viral replication and HIV-1 strains resistant to multiple antiretroviral agents. ${ }^{29}$

\section{EXPERIMENTAL PROCEDURES}

\section{General experimental procedures}

NMR data were acquired on a Varian VNMRS $600 \mathrm{MHz}$ NMR spectrometer and LC-HRESIMS data obtained by using a LTQ/XL Orbitrap coupled to the HPLC system (PDA detector, PDA autosampler and pump) under the following conditions: capillary voltage of $45 \mathrm{~V}$, capillary temperature of $260^{\circ} \mathrm{C}$, auxiliary gas flow rate of 10-20 arbitrary units, sheath gas flow rate of 40-50 arbitrary units, spray voltage of $4.5 \mathrm{kV}$ with a mass range of 100-2000 a.m.u. (maximal resolution of 30 000). For LC/MS, a C18 analytical HPLC column $(5 \mu \mathrm{m}, 4.6 \mathrm{~mm} \times 150 \mathrm{~mm})$ was used with a mobile phase of $0-100 \% \mathrm{MeOH}$ over $30 \mathrm{~min}$ at a flow rate of $1 \mathrm{ml} \mathrm{min}^{-1}$. Optical rotations were recorded using a Bellingham+Stanley ADP410 polarimeter. Medium Pressure Liquid Chromatographic separations were carried out using a Biotage SP1 flash system fitted with a reversed phase 40iM cartridge (KP-C18-HS, $40 \times 150 \mathrm{~mm}$ ), the detection was carried out at 220 and $254 \mathrm{~nm}$. For RP-HPLC separations, a SunFire $\left(\mathrm{C}_{18}, 250 \times 10 \mathrm{~mm}, 5 \mu \mathrm{m}\right.$ i.d. $)$ column connected to an Agilent 1200 series binary pump was used and monitored with an Agilent photodiode array detector, the detection was carried out at 220, 254, 280 and $320 \mathrm{~nm}$. Acid hydrolysis of the isolated compounds was performed as reported before. ${ }^{30}$ HPLC solvents and the authentic sugar samples were obtained from Sigma-Aldrich, Irvine, Ayrshire, UK, the ingredients for fermentation were from Oxoid UK and Sigma-Aldrich and the Diaion HP-20 resin from Resindion S.R.L., a subsidiary of Mitsubishi Chemical Co., Binasco, Italy.

\section{Microbial taxonomy and fermentation conditions}

Strain H45 was isolated from a subsurface soil sample collected at 5048 meters above sea level on the Chajnantor plateau, in northeast Chile $\left(23^{\circ} 00^{\prime} 48.8^{\prime \prime} \mathrm{S} /\right.$ $67^{\circ} 45^{\prime} 30.8^{\prime \prime} \mathrm{W}$ ) by one of us (MG) in November 2012. The strain was isolated on Gauze's No. 1 agar $^{31}$ supplemented with the antifungal antibiotics cycloheximide and nystatin (each at $25 \mu \mathrm{g} \mathrm{ml}^{-1}$ ) using the procedure described by Okoro et al. ${ }^{8}$ The strain has phenotypic properties consistent with its classification in the genus Lentzea and forms a distinct phyletic line in the Lentzea 16S rRNA gene tree. The Lentzea isolate has been deposited in the NCIMB and NRRL public service collections under the accession numbers 14966 and B-65282, respectively, the GenBank accession number of the $16 \mathrm{~S}$ rRNA gene sequence of the strain is LT009512. Two cultivation media were used for large scale fermentation of the strain: medium 410 contained glucose $(10.0 \mathrm{~g})$, glycerol $(10.0 \mathrm{~g})$, casamino acids $(15.0 \mathrm{~g})$, oatmeal $(5.0 \mathrm{~g})$, peptone $(10.0 \mathrm{~g})$, yeast extract $(5.0 \mathrm{~g}), \mathrm{CaCO}_{3}(1.0 \mathrm{~g})$ and distilled water to $1 \mathrm{l}, \mathrm{pH} 7.0$; and modified ISP2 medium malt extract $(4.0 \mathrm{~g})$, yeast extract $(10.0 \mathrm{~g})$, dextrose $(10.0 \mathrm{~g})$, glycerol $(10.0 \mathrm{~g})$ and distilled water to $11, \mathrm{pH} 7.0$. The strain was grown in 41 of each of these media by shaking at 180 r.p.m. in a shaker incubator at $30^{\circ} \mathrm{C}$ for 7 days when HP-20 resin beads was added followed by shaking at 180 r.p.m. for $6 \mathrm{~h}$ before centrifugation at 3000 r.p.m. for $15 \mathrm{~min}$.

\section{Extraction and isolation}

Biomass of the strain H45 and HP-20 resin beads were extracted with methanol $(\mathrm{MeOH} \times 2)$ and acetone $(\times 1)$ and the resultant extracts combined and concentrated in vacuo. The combined extracts were purified using the Biotage flash system with a gradient of $\mathrm{MeOH}$ in water $(5-100 \%$ in 12 column volumes). The eluted fractions of both media were screened using LCMS and ${ }^{1} \mathrm{H}$ NMR and the interesting fractions further purified using reversed phaseHPLC. For medium 410, the second fraction was purified using a gradient of $\mathrm{MeOH}$ in $\mathrm{H}_{2} \mathrm{O} / \mathrm{MeOH}\left(95: 5 ; 25-100 \%\right.$ in $25 \mathrm{~min}$, flow rate $\left.2.0 \mathrm{ml} \mathrm{min}^{-1}\right)$ to obtain compounds $\mathbf{1}$ (3.1 mg), 2 (1.0 mg), 3 (2.2 mg), 4 (1.0 mg) and 5 $(2.0 \mathrm{mg})$. In the case of the modified ISP2 medium, the fourth fraction was purified using a gradient of $\mathrm{MeOH}$ in $\mathrm{H}_{2} \mathrm{O} / \mathrm{MeOH}(95: 5 ; 50-100 \%$ in 25 min, flow rate $2.2 \mathrm{ml} \mathrm{min}^{-1}$ ) to obtain compounds 1 (3.1 mg), 2 (1.1 mg), 5 (3.4 mg), 6 (3.4 mg) and $7(2.2 \mathrm{mg})$.

Lentzeoside A (1). Light yellow powder; $[\alpha]^{20}{ }_{\mathrm{D}}-25$ (c $\left.0.15, \mathrm{MeOH}\right)$; UV $(\mathrm{MeOH}) \lambda_{\max }(\log \varepsilon)$ at $258(3.2), 268(3.6)$ and $280(2.7) \mathrm{nm} ;{ }^{1} \mathrm{H}$ and ${ }^{13} \mathrm{C}$ NMR data (Tables 1 and 2); HRESIMS $m / z[\mathrm{M}+\mathrm{Na}]^{+}$at 281.1351 indicting the molecular formula $\mathrm{C}_{13} \mathrm{H}_{22} \mathrm{O}_{5}$ (calculated $[\mathrm{M}+\mathrm{Na}]^{+}$ion at $\mathrm{m} / \mathrm{z} 281.1359$ ).

Lentzeoside $B$ (2). Light yellow powder; $[\alpha]^{20} \mathrm{D}-31$ (c $\left.0.18, \mathrm{MeOH}\right)$; UV $(\mathrm{MeOH}) \lambda_{\max }(\log \varepsilon)$ at $258(3.1), 270$ (3.4) and $280(2.5) \mathrm{nm} ;{ }^{1} \mathrm{H}$ and ${ }^{13} \mathrm{C}$ NMR data (Tables 1 and 2); HRESIMS $m / z[\mathrm{M}+\mathrm{Na}]^{+}$at 281.1351 indicting the molecular formula $\mathrm{C}_{13} \mathrm{H}_{22} \mathrm{O}_{5}$ (calculated $[\mathrm{M}+\mathrm{Na}]^{+}$ion at $\mathrm{m} / \mathrm{z} 281.1359$ ).

Lentzeoside C (3). Light yellow powder; $[\alpha]^{20}{ }_{\mathrm{D}}+38$ (c $\left.0.10, \mathrm{MeOH}\right)$; UV $(\mathrm{MeOH}) \lambda_{\max }(\log \varepsilon)$ at $258(3.2), 274(3.8)$ and $282(2.9) \mathrm{nm} ;{ }^{1} \mathrm{H}$ and ${ }^{13} \mathrm{C}$ NMR data (Tables 1 and 2); HRESIMS $m / z[\mathrm{M}+\mathrm{Na}]^{+}$at 297.1299 indicting the molecular formula $\mathrm{C}_{13} \mathrm{H}_{22} \mathrm{O}_{6}$ (calculated $[\mathrm{M}+\mathrm{Na}]^{+}$ion at $\mathrm{m} / z$ 297.1309).

Lentzeoside $D$ (4). Light yellow powder; $[\alpha]^{20}{ }_{\mathrm{D}}-22$ (c $\left.0.18, \mathrm{MeOH}\right)$; UV $(\mathrm{MeOH}) \lambda_{\max }(\log \varepsilon)$ at $258(3.1), 270(3.4)$ and $280(2.5) \mathrm{nm} ;{ }^{1} \mathrm{H}$ and ${ }^{13} \mathrm{C}$ NMR data (Tables 1 and 2); HRESIMS $m / z[\mathrm{M}+\mathrm{Na}]^{+}$at 281.1349 indicting the molecular formula $\mathrm{C}_{13} \mathrm{H}_{22} \mathrm{O}_{5}$ (calculated $[\mathrm{M}+\mathrm{Na}]^{+}$ion at $\mathrm{m} / z$ 281.1359).

Lentzeoside E (5). Colorless powder; $[\alpha]^{20}{ }_{\mathrm{D}}-29$ (c 0.15, MeOH); UV (MeOH) $\lambda_{\max }(\log \varepsilon)$ at $239(3.6) \mathrm{nm} ;{ }^{1} \mathrm{H}$ and ${ }^{13} \mathrm{C}$ NMR data (Tables 1 and 2 ); HRESIMS $\mathrm{m} / \mathrm{z}[\mathrm{M}+\mathrm{Na}]^{+}$at 269.1351 indicting the molecular formula $\mathrm{C}_{12} \mathrm{H}_{22} \mathrm{O}_{5}$ (calculated $[\mathrm{M}+\mathrm{Na}]^{+}$ion at $m / z$ 269.1359).

Lentzeoside F (6). Colorless powder; $[\alpha]^{20}{ }_{\mathrm{D}}-25$ (c 0.18, MeOH); UV (MeOH) $\lambda_{\max }(\log \varepsilon)$ at $241(3.4) \mathrm{nm} ;{ }^{1} \mathrm{H}$ and ${ }^{13} \mathrm{C}$ NMR data (Tables 1 and 2); HRESIMS $m / z[\mathrm{M}+\mathrm{H}]^{+}$at 247.1545 indicting the molecular formula $\mathrm{C}_{12} \mathrm{H}_{22} \mathrm{O}_{5}$ (calculated $[\mathrm{M}+\mathrm{H}]^{+}$ion at $\mathrm{m} / \mathrm{z} 247.1540$ ).

\section{Anti-HIV-1 integrase activity}

The HIV-1 integrase inhibitory activities of compounds 1-6 were evaluated using a kit purchased from XpressBio Life Science Products (Frederick, MD 21705, USA) and by following the manufacturer's protocol. In brief, biotin-linked HIV-1 LTR U5 donor substrate (DS) DNA was applied to a streptavidin-coated 96-well plate, the test compounds were then added along with target substrate DNA and HIV integrase. The integrase processes the HIV-1 LTR U5 and catalyzes the strand transfer recombination reaction to integrate the DS DNA into the target substrate DNA. The products of these reactions were detected colorimetrically using an HRP-labeled antibody, sodium azide was used as a positive inhibitory control. Each compound was tested at four different concentrations $(100,50,12.5$ and $3.1 \mu \mathrm{M})$ in triplicate.

\section{CONFLICT OF INTEREST}

The authors declare no conflict of interest.

\section{ACKNOWLEDGEMENTS}

We thank the College of Physical Sciences, University of Aberdeen, for provision of infrastructure and facilities in the Marine Biodiscovery Centre, and staff at the European Southern Observatory for permission and assistance in collecting soil samples from the Chajnantor plateau. ATB and JAA thank The Royal Society for support (International Joint Project Grant JP 100654). JAA thanks Conicyt for the Basal Grant FB0001 for the Centre CeBiB. HI is grateful for a scholarship from the Malaysian Government and MG for an Emeritus Fellowship from the Leverhulme Trust.

1 Harvey, A. L., Edrada-Ebel, R. \& Quinn, R. J. The re-emergence of natural products for drug discovery in the genomics era. Nat. Rev. Drug Discov. 14, 111-129 (2015).

2 Pidot, S. J., Coyne, S., Kloss, F. \& Hertweck, C. Antibiotics from neglected bacterial sources. Int. J. Med. Microbiol. 304, 14-22 (2014). 
3 Bull, A. T. in Extremophiles Handbook Vol. 2 (eds Horikoshi, K., Antranikian, G., Bull, A. T., Robb, F. \& Stetter, K.) 1203-1240 (Springer-Verlag, 2011)

4 Gómez-Silva, B., Rainey, F. A., Warren-Rhodes, K. A., McKay, C. P. \& Navarro-González, R. in Microbiology of Extreme Soils, Soil Biology Vol. 13 (eds Dion, P. \& Nautiyal, C. S.) 117-132 (Springer, Berlin, 2008)

5 Navarro-González, R. et al. Mars-Like soils in the Atacama Desert, Chile, and the dry limit of microbial Life. Science 302, 1018-1021 (2003).

6 Crits-Christoph, A. et al. Colonization patterns of soil microbial communities in the Atacama Desert. Microbiome 1, 28 (2013).

7 Bull, A.T. et al. The Atacama Desert: technical resources and the growing importance of novel microbial diversity. Ann. Rev. Microbiol. 70: (2016).

8 Okoro, C. K. et al. Diversity of culturable actinomycetes in hyper-arid soils of the Atacama Desert, Chile. Antonie van Leeuwenhoek 95, 121-133 (2009).

9 Bull, A. T. \& Asenjo, J. A. Microbiology of hyper-arid environments: recent insights from the Atacama Desert, Chile. Antonie van Leeuwenhoek 103, 1173-1179 (2013).

10 Rateb, M. E. et al. Chaxamycins A-D, bioactive ansamycins from a hyper-arid desert Streptomyces sp. J. Nat. Prod. 74, 1491-1499 (2011).

11 Rateb, M. E. et al. Diverse metabolic profiles of a Streptomyces strain isolated from a hyper-arid environment. J. Nat. Prod. 74, 1965-1971 (2011).

12 Schulz, D. et al. Abenquines A-D: aminoquinone derivatives produced by Streptomyces sp. strain DB634. J. Antibiot. 64, 763-768 (2011).

13 Nachtigall, J. et al. Atacamycins A-C, 22-membered antitumor macrolactones produced by Streptomyces sp. C38. J. Antibiot. 64, 775-780 (2011).

14 Elsayed, S. S. et al. Chaxapeptin, a lasso peptide from extremotolerant Streptomyces leeuwenhoekii strain C58 from the hyperarid Atacama Desert. J. Org. Chem. 80, 10252-10260 (2015).

15 Busarakam, K. et al. Streptomyces leeuwenhoekii sp. nov., the producer of chaxalactins and chaxamycins, forms a distinct branch in Streptomyces gene trees. Antonie van Leeuwenhoek 105, 849-861 (2014).

16 Gomez-Escribano, J. P. et al. The Streptomyces leeuwenhoekii genome: de novo sequencing and assembly in single contigs of the chromosome, circular plasmid pSLE1 and linear plasmid pSLE2. BMC Genomics 16, 485 (2015).

17 Craigie, R. HIV integrase, a brief overview from chemistry to therapeutics. J. Biol. Chem 276, 23213-23216 (2001).
18 Craigie, R. The road to HIV-1 integrase inhibitors: the case for supporting basic research. Future Virol. 9, 899-903 (2014)

19 Labeda, D. P. in Bergey's Manual of Systematic Bacteriology 2nd end, Vol. 5 (eds Goodfellow, M. et al.) 1379-1383 (Springer, New York, NY, USA, 2012)

20 Cao, C.-L. et al. Lentzea guizhouensis sp. nov., a novel Lithophilous actinobacterium isolated from limestone from the Karst area, Guizhou, China. Antonie van Leeuwenhoek 108, 1365-1372 (2015)

21 Kiuchi, F. et al. Acacia concinna Saponins. II. Structure of monoterpenoid glycosides in the alkaline hydrolysate of the saponin fraction. Chem. Pharm. Bull. 45, 807-812 (1997).

22 Francis, J et al. Insulin Secretagogues from Moringa oleifera with cyclooxygenase enzyme and lipid peroxidation inhibitory activities. Helv. Chim. Acta 87, 317-326 (2004).

23 Fujimoto, H. \& Isomura, M. Chemical studies on chinese traditional medicine, Dangshen. I. Isolation of (Z)-3- and (E)-2-hexenyl $\beta$-D-glucosides. Biosci. Biotechnol. Biochem. 36, 2689-2690 (1988).

24 Miyase, T. et al. Studies on the glycosides of Epimedium grandiflorum MORR. var. thunbergianum (MIQ.) NAKAI. III. Chem. Pharm. Bull. 36, 2475-2484 (1988).

25 Yassin, A. F. et al. Lentzea gen. nov., a new genus of the order Actinomycetales. Int. J. Syst. Bacteriol. 45, 357-363 (1995).

26 Sasamura, S. et al. Bioconversion of FR901459, a novel derivative of cyclosporin A, by Lentzea sp. 7887. J. Antibiot. 68, 511-520 (2015).

27 Maes, M., Loyter, A. \& Friedler, A. Peptides that inhibit HIV-1 integrase by blocking its protein-protein interactions. FEBS J. 279, 2795-2809 (2012).

28 Sherman, M. P. \& Greene, W. C. Slipping through the door: HIV entry into the nucleus. Microbes Infect. 4, 67-73 (2002).

29 Hicks, C. \& Gulick, R. M. Raltegravir: the first HIV type 1 integrase inhibitor. Clin. Infect. Dis. 48, 931-939 (2009).

30 Nakanishi, T., Inada, A., Kambayashi, K. \& Yoneda, K. Flavonoid glycosides of the roots of Glycyrrhiza uralensis. Phytochemistry 24, 339-341 (1985).

31 Zakharova, O. S., Zenova, G. M. \& Zvyagintsev, D. G. Some approaches to the selective isolation of actinomycetes of the Genus Actinomadura from soil. Microbiology 72 110-113 (2003).

Supplementary Information accompanies the paper on The Journal of Antibiotics website (http://www.nature.com/ja) 